\title{
Per-capita consumption of analgesics: a nine-country survey over 20 years
}

\author{
H.-C. Diener $\cdot$ R. Schneider $\cdot$ B. Aicher
}

Received: 14 March 2008/ Accepted: 21 May 2008/Published online: 10 July 2008

(C) Springer-Verlag 2008

\begin{abstract}
There are no reliable data at present on use of analgesics in various countries. We compared per-capita consumption in nine different countries during the period 1986-2005. The per-capita consumption was calculated on the basis of the sales figures of distributors to pharmacies and direct purchases by pharmaceutical companies in a sample of 1,000 pharmacies. The countries studied were: Australia, Austria, Belgium, Canada, France, Germany, Sweden, Switzerland, and the USA. In international comparison Austria, Switzerland, and Germany showed the lowest per-capita consumption of analgesics (approx. 4050 Standard Units (SU) per capita per year), while in Sweden and France consumption was three times as high. The correlation analysis over the various countries and time points confirmed a significant correlation between use of single analgesics and overall use of analgesics. In Germany, where an allegedly particularly high and constantly rising analgesic use has been discussed controversially (Meiner, Pharm Ind 49:1247-1251, 1987), per-capita consumption of analgesics from 1980 to 2005 remained practically unchanged at approx. $50 \mathrm{SU}$ per capita per year. The prevalence of conditions inducing analgesic use shows appropriate analgesics use on an overall population level.
\end{abstract}

Keywords Headache $\cdot$ Migraine $\cdot$ Tension-type headache · Analgesics · OTC · Drug consumption

H.-C. Diener ( $\square)$

Department of Neurology,

University Duisburg-Essen, Essen, Germany

e-mail: hans.diener@uni-duisburg-essen.de

R. Schneider - B. Aicher

Boehringer Ingelheim Pharma GmbH \& Co. KG,

Ingelheim, Germany

\section{Introduction}

Life-time prevalence of acute pain, in particular headache, is assumed to be nearly $100 \%$. This means that, i.e. almost every individual will suffer from some kind of pain (e.g. headache) during their lifetime. Life-time headache prevalence alone is $66 \%$ worldwide, in adults in Europe it is $80 \%$ for tension-type headache, and $15 \%$ for migraine [1]. In most cases analgesics are used for treatment. Painrelieving therapy is generally symptom-prompted and common types of acute pain, such as episodic tension-type headache or migraine with or without aura, often does not require intervention by a doctor. This explains why analgesics are among the drugs most frequently used in selfmedication. High safety and good tolerability of a drug are critical for its OTC authorisation [2]. However, adverse effects of drugs intended for self-medication cannot be completely ruled out. Since most adverse drug effects are dose-related, consumption of drugs - for self-medication in particular analgesics-is often in the focus of public interest. Reliable long-term data on the use of analgesics in different countries are only available for the period from 1970 to 1986 [3]. The purpose of the present examination was to close the gap over the past 20 years and to provide a database for further analyses such as epidemiological studies or studies on the usage pattern of OTC analgesics.

\section{Methods}

Data on pharmacies purchases including all sales of the distributors to pharmacies and, in addition, direct purchases of pharmacies from pharmaceutical companies were obtained for a sample of 1,000 pharmacies (statistics by the Institute of Medical Statistics, IMS, Frankfurt). "These 
consumption data" represent the quantities available for sale in the pharmacies. Correction for unused tablets due to expiry is not possible since no valid data are available.

Figures from 1986 onwards were available for the following countries: Germany, Switzerland, Austria, Belgium, Canada, Australia, France, Sweden, and the USA. No figures were available from the USA for 1995. Except for the first reading point in 1986, the analysis was performed in 5 -year intervals.

We began by comparing the different countries that were compared over the period from 1986 to 2005 and followed this with an exemplary analysis of the situation in Germany since 1980 by comparing Germany (West) with Germany (all) and prescription with non-prescription analgesics. Long-term trends could only be shown for the former western part of Germany as no long-term data are available for the former eastern part.

Only analgesics of ATC code (Anatomical Therapeutic Chemical Classification System as provided by the WHO) N2B (general analgesics) were included; narcotics (N2A), migraine remedies (N2C), and spasmolytics (A3D) were not considered for this analysis. N2B analgesics include both prescription and non-prescription analgesics. Their compositions were identified by using international drug directories (e.g. Rote Liste for Germany, Physician's Desk Reference for the USA). In Germany, the substances of nonprescription N2B analgesics include acetylsalicylic acid (ASA), paracetamol or ibuprofen, either as single agents or in combination. The N2B prescription drugs in Germany include substances such as metamizole, tilidine plus naloxone, codeine, or tramadol as single agents or in combination.

Sales figures were converted into standardised units (SU) in order to control for the different package sizes and formulations (see Appendix 1). The conversion formulas varied depending on the different formulations. For many products one tablet equaled 1 SU. Per-capita consumption was calculated by dividing the defined SU by the official population figures in the respective countries and years (data obtained from Statistisches Bundesamt, Wiesbaden, Germany).

For further analysis the following categories were created according to the number of agents: (A1) single analgesics (contain 1 agent); (A2) combination analgesics (contain two agents at least, e.g. paracetamol, acetylsalicylic acid, codeine, caffeine, or phenacetin). In another analysis, category A2 was subdivided into: (A21) caffeine-containing multiple combination analgesics with two analgesic agents at least plus caffeine, and (A22) other combination analgesics. Low-dose ASA products $(\leq 300 \mathrm{mg}$ for platelet aggregation inhibition/prevention of vascular events) were not counted among the analgesics and remained unconsidered. Preparations containing vitamins and one analgesic substance were classified as single analgesics. Products with one analgesic agent plus caffeine as second agent were considered combination analgesics.

\section{Results}

International analysis

The international comparison for 2005 shows that the highest per-capita consumption among the countries included was observed in Sweden (147 SU per inhabitant, Fig. 1), followed by France with $141 \mathrm{SU}$, Australia with 106, Canada with 81, Belgium with 66 , and the USA with 61 SU. Germany (All) with 51 SU, Switzerland with 46, and Austria with $42 \mathrm{SU}$ showed the lowest per-capita consumption in international comparison. Per-capita consumption in Austria, Switzerland and Germany is only onethird to one half that in other countries. The development from 1986 to 2005 reveals two groups: One group with Germany, Austria, Switzerland and Belgium, whose percapita consumption was between 40 and 65 SU per year
Fig. 1 International comparison of analgesics consumption in the year 2005

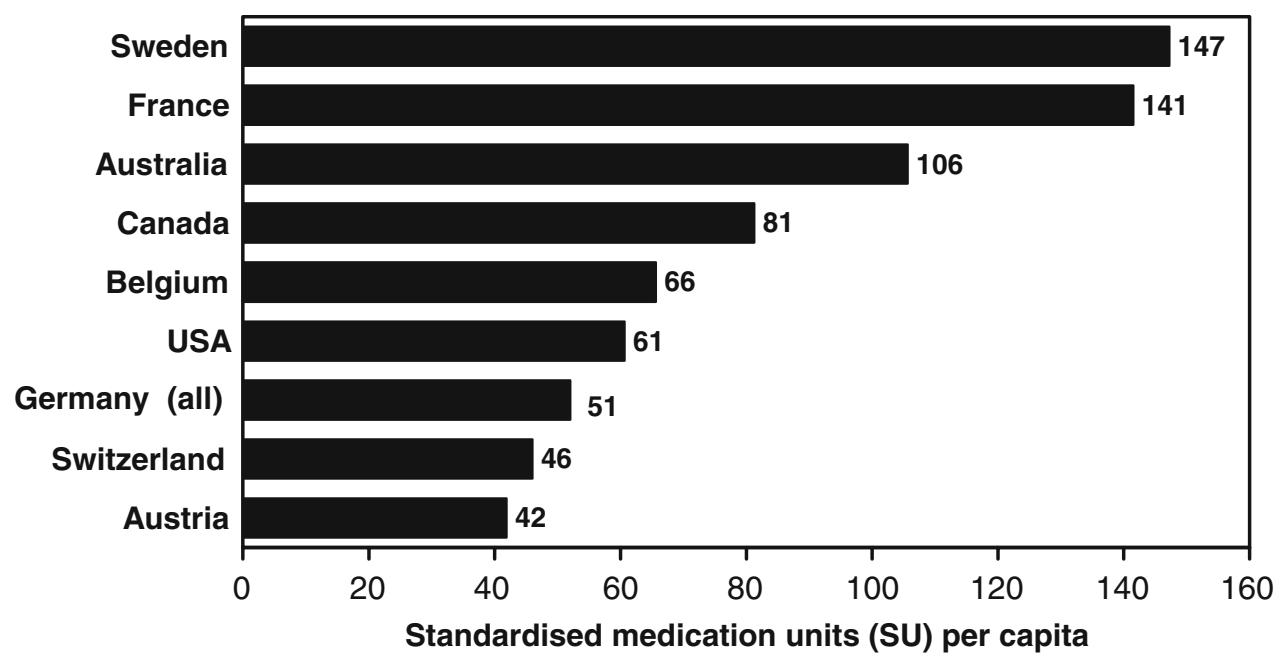


Fig. 2 Trend of analgesic consumption comparing all analgesics with single analgesics in the years 1986 , 1990, 1995, 2000, 2005 (data for 1995 in USA not available)
Fig. 3 Trend of analgesic consumption comparing all analgesics with caffeinecontaining multiple analgesic combinations in the years 1986 1990, 1995, 2000, 2005 (data for 1995 in USA not available)
Standardised medication units (SU) per capita

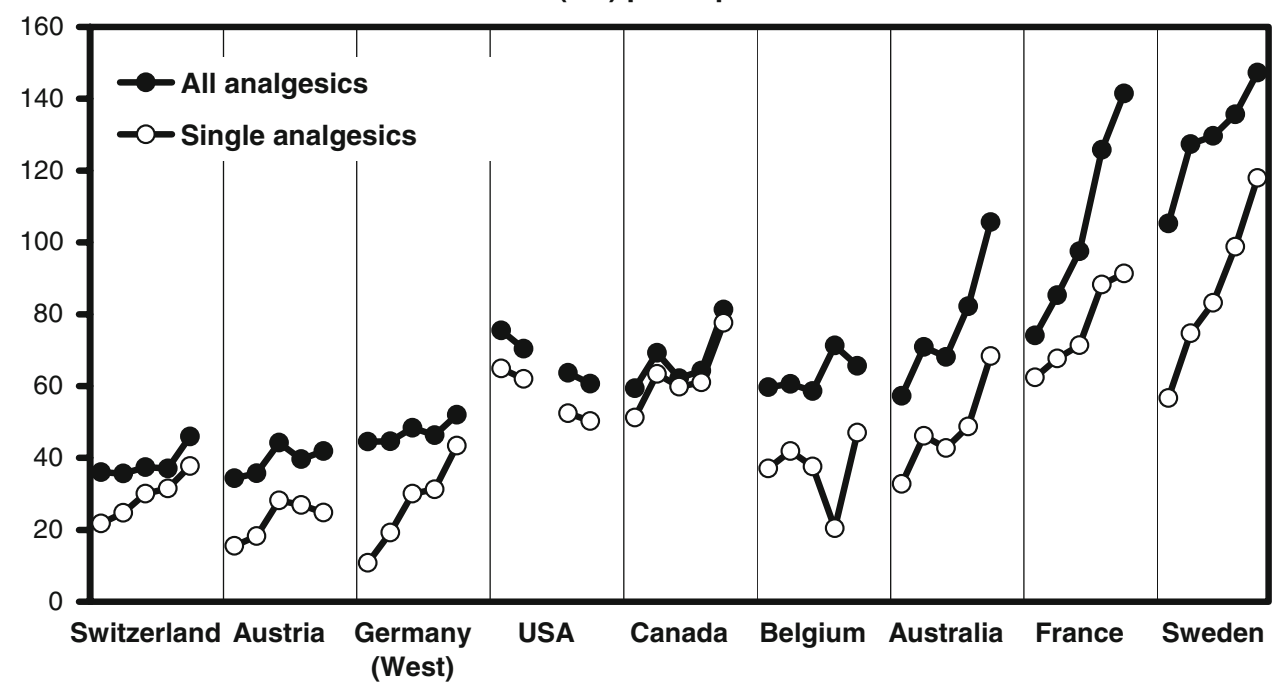

Standardised medication units (SU) per capita

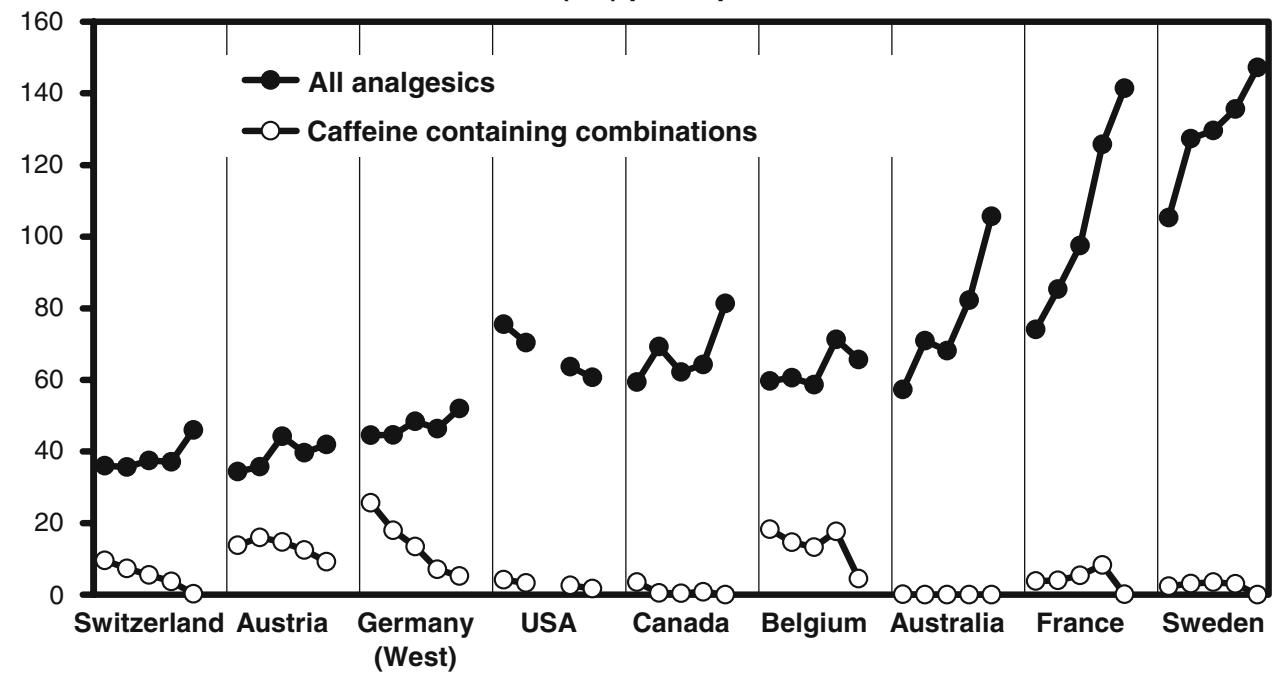

Table 1 Relative proportions of standardised medication units (SU) among different countries comparing weighted and unweighted proportions

\begin{tabular}{lll}
\hline $\begin{array}{l}\text { Relative proportions } \\
\text { of ASA consumption }\end{array}$ & $\begin{array}{l}\text { Unweighted } \\
(\%)\end{array}$ & $\begin{array}{l}\text { Weighted by } \\
\text { mg ASA (\%) }\end{array}$ \\
\hline USA & 48.3 & 58.2 \\
Germany (West) & 19.7 & 16.0 \\
Canada & 10.7 & 12.2 \\
France & 16.7 & 9.7 \\
Sweden & 1.3 & 1.1 \\
Switzerland & 0.8 & 0.7 \\
Austria & 1.8 & 1.7 \\
Belgium & 0.6 & 0.3 \\
Australia & 0.1 & 0.1 \\
Total 9 Countries & 100 & 100 \\
\hline
\end{tabular}

$100 \%=$ overall consumption of acetylic salicylic acid (ASA) among 9 countries and remained constant or showing a minor increase only (Switzerland, Belgium) during this period (Fig. 2). In the other group, comprising Canada, Australia, France, and Sweden, per-capita consumption in 1986 was distinctly higher than in the first group, ranging between 57 SU (Aus) to $105 \mathrm{SU}(\mathrm{S})$.

The up to threefold higher consumption in Sweden and France cannot be explained by use of products with basically different compositions, e.g. ASA products. Comparisons between an unweighted presentation and a presentation weighted with mg ASA reveals no significant differences in the distribution of the SU values of ASA single products (Table 1). The weighting takes into account the different ASA doses per SU by multiplying the respective consumption figures (SU figures) per product by the corresponding weighting factor (equivalent ASA dose in $\mathrm{mg}$ ) and dividing by the sum of the weighting factors. 
Fig. 4 Ecological analysis between consumption of all analgesics with single analgesics in the years 1986 , 1990, 1995, 2000, 2005 considering the countries Switzerland, Germany (West), France, USA, Canada, Belgium, Austria, Sweden and und Australia (data for 1995 in USA not available)
Fig. 5 Ecological analysis between consumption of all analgesics with caffeinecontaining multiple analgesic combinations in the years 1986 , 1990, 1995, 2000, 2005 considering the countries Switzerland, Germany (West), France, USA, Canada, Belgium, Austria, Sweden and und Australia (data for 1995 in USA not available)
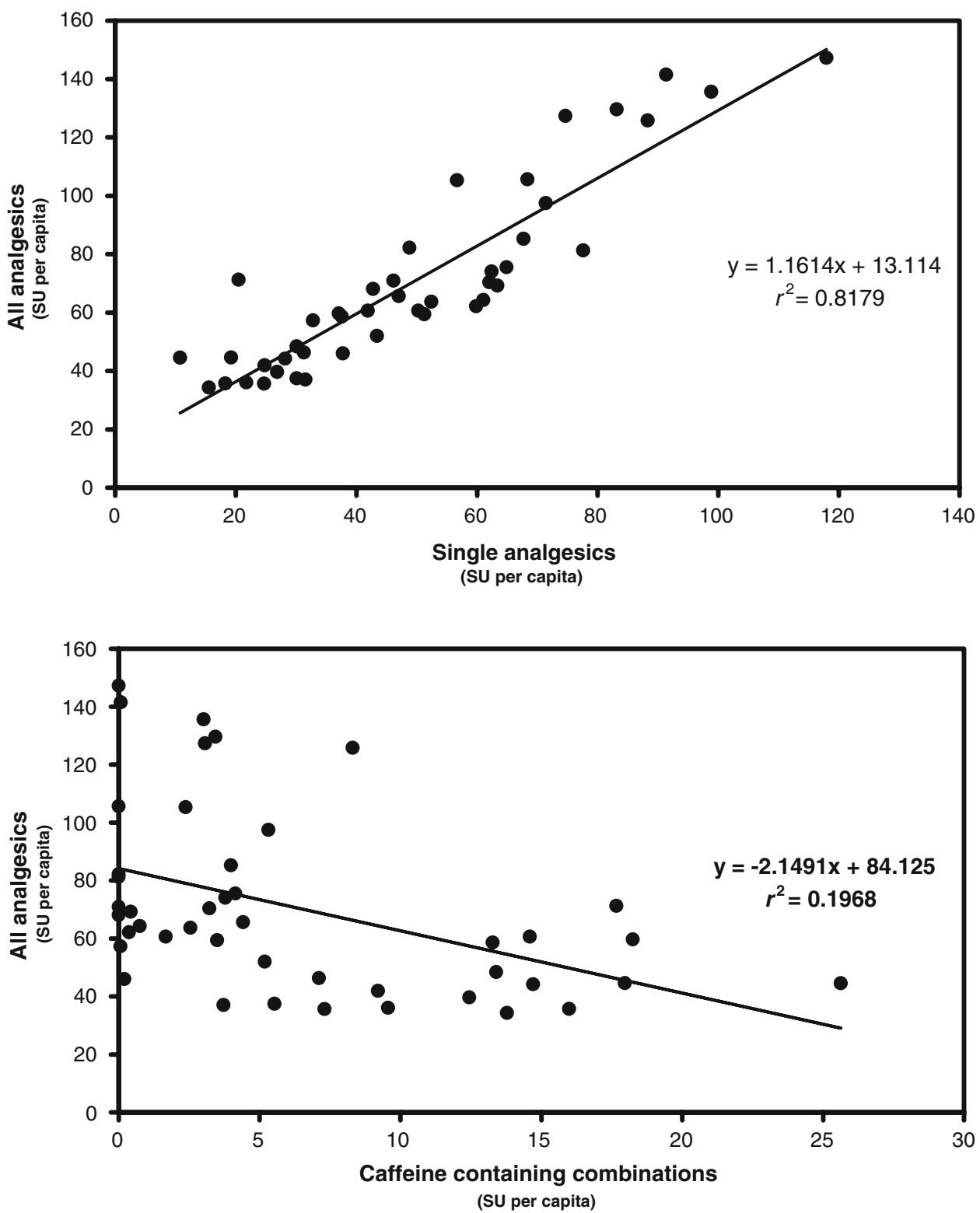

It stands out that in countries with high analgesic use, such as Sweden and France, consumption increased again considerably between 1986 and 2005 to 141 (F) and 147 (S) (Fig. 2). In both absolute figures and percentages, this increase is clearly higher than in the first group. In the first group annual consumption increased in Germany (West) from 45 to $52 \mathrm{SU}(+16 \%)$ and in Switzerland from 35 to $46 \mathrm{SU}(+31 \%)$. In the second group, in contrast, consumption increased in Australia from 57 to $106 \mathrm{SU}$ $(+86 \%)$, in France from 74 to $141(+91 \%)$, and in Sweden from 105 to $147 \mathrm{SU}(+40 \%)$.

The high per-capita consumption in Sweden and France is based on a high increase in single products in the past 15 to 20 years (Fig. 2); this is also true of Australia (third highest analgesic use). In Germany and Switzerland the use of single analgesics has also increased over the past 20 years- associated with a (minor) increase in overall analgesic consumption over the last 5 years. In the past a short-term increase in single analgesics in Austria caused a higher overall consumption in 1995, which subsided thereafter, accompanied by a decrease in single analgesics. Today Austria has the lowest rate of single products in international comparison and the lowest total consumption of all countries studied. In the USA a reduction in the use of single products is accompanied by a decrease in overall consumption.

Caffeine-containing multiple combinations (at least two analgesic agents plus caffeine) are of minor relevance in international comparison and do not explain the increasing overall use in some countries (Fig. 3).

The correlation analysis across different countries and time points confirms the association between the use of single analgesics and overall analgesic use (Fig. 4). We 
showed that a strong relationship $\left(r^{2}=81.8 \%\right)$ exists between the consumption of single analgesics and total analgesic consumption.

In contrast, only a very weak correlation - and a negative one-can be observed between caffeine-containing multiple combinations and overall consumption $\left(r^{2}=19.7 \%\right.$; Fig. 5). This supports the statement that this product group of multiple combinations does not contribute to the increased use on a population level, but rather even counteracts higher overall consumption.

\section{Analysis Germany}

Per-capita consumption of analgesics in Germany (West) has been very stable over the past 25 years and, at 52 SU per capita per year, is currently slightly higher than the long-term average (increase since 2000: approx. +1 SU p.a.). There is no difference between Germany (West) and Germany (all) (Fig. 6).
Most of the analgesics of the N2B market considered here (market for general analgesics) can be bought without prescription over the counter in pharmacies (Fig. 7). Between 1986 and 1995 the consumption of prescriptionfree analgesics increased markedly from 25.0 to $42.7 \mathrm{SU}$ per capita per year and in 1995 comprised approx. 88\% of all analgesics used, while the percentage of prescription analgesics decreased by approx. $71 \%$. This picture has been changing since 1995 with prescription analgesics tripling to approx. $18 \mathrm{SU}$ per capita per year, while the OTC analgesics decreased by approx. $19 \%$. The increase in prescription drug consumption since 1995 is primarily responsible for the slight increase in overall analgesics and is now back at the level of 1986. No consumption of any phenacetin-containing analgesics has been observed in Germany since 1986.

In 2005 in the prescription (Rx) group of N2B analgesics, combination products accounted for approx. $42 \%$ of all $\mathrm{Rx}$ analgesics in terms of SU. The most important
Fig. 6 Trend of analgesic consumption in Germany (West) from 1980 until 2005; Comparison between Germany (West) and Germany (all) in the year 2005

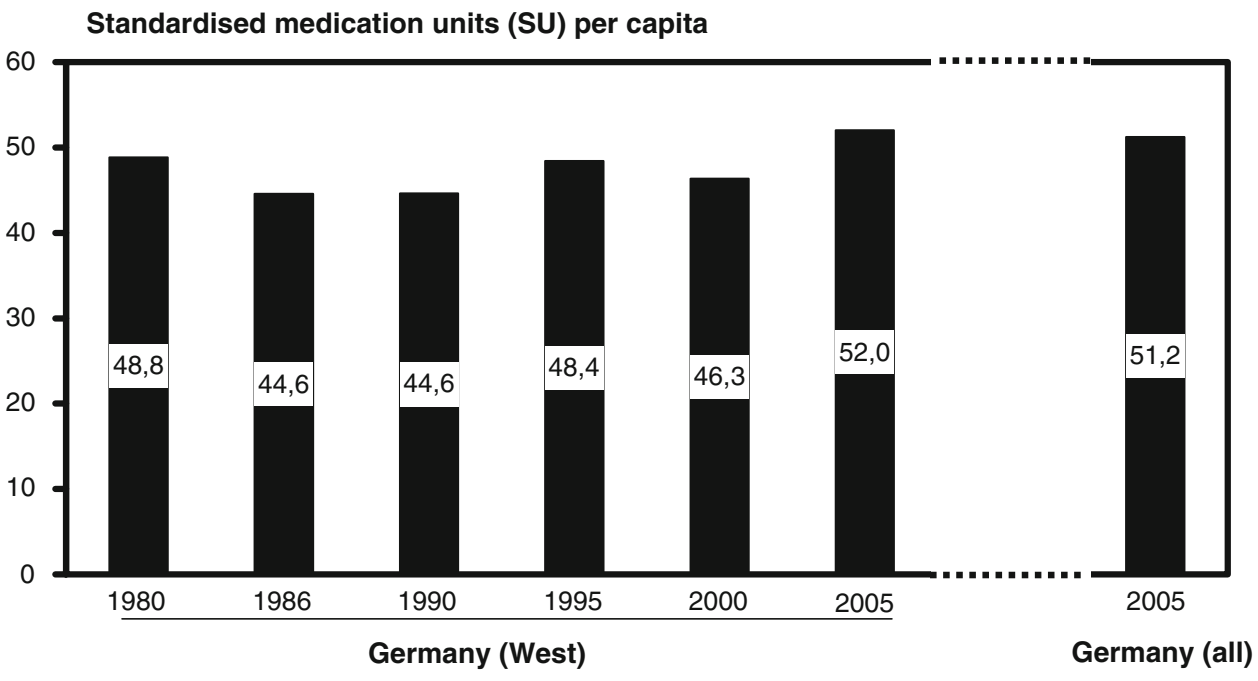

Fig. 7 Trend of analgesic consumption in Germany (West) from 1980 until 2005 comparing prescription-free (OTC) with prescription (Rx) analgesics
Standardised medication units (SU) per capita

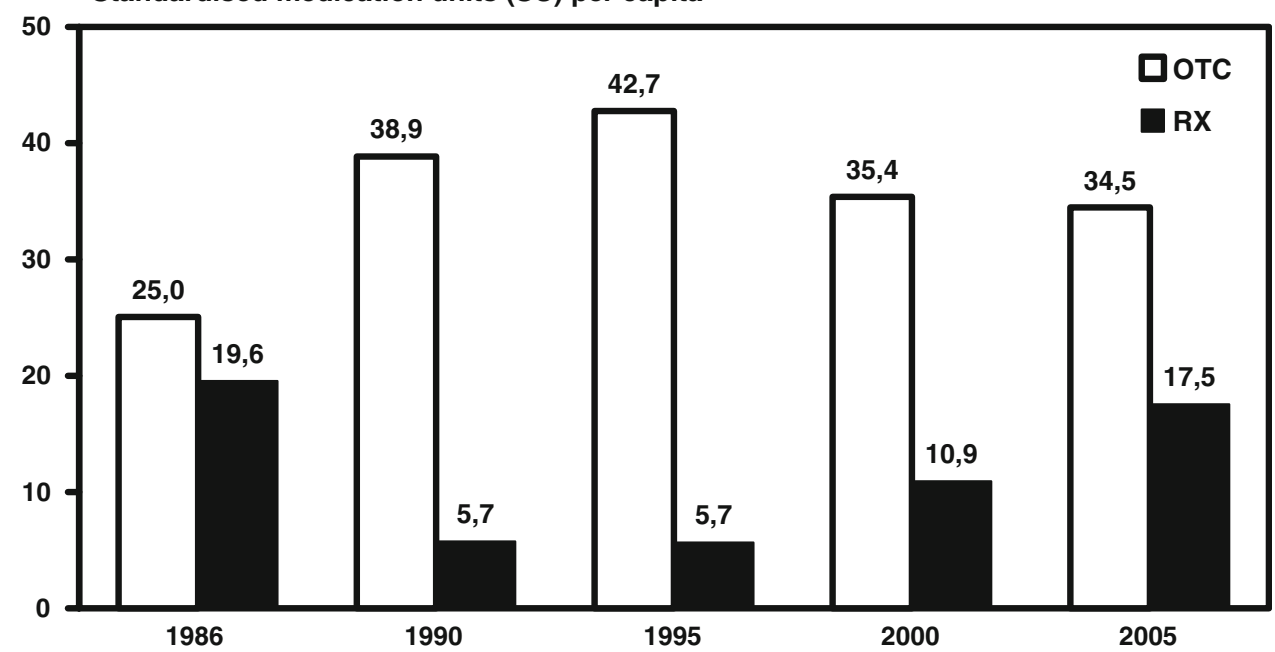


combinations are codeine plus paracetamol (18\% of all SU in the Rx group), followed by tilidine plus naloxone (12\%). The predominating single products in the $\mathrm{Rx}$ group are metamizole $(28 \%)$ and tramadol $(23 \%)$. Growth in the $\mathrm{Rx}$ group can be seen for both the combinations named and the single products.

\section{Discussion}

This is the first investigation providing reliable, internationally comparable analyses of analgesic use in nine countries over a period of 20 years. The data from the database of the Institute of Medical Statistics provide a sound and valid basis. The "consumption data" collected represent the supplies available for sale in the pharmacies. Because of the nature of per-capita consumption data it is theoretically possible that the amounts of unused (expired) medications might be different in the various countries. However, no data on this are available. Even if we assume that such differences exist, it is hardly conceivable that the differences in unused medication between countries would be high enough to explain the considerable differences in per-capita consumption alone.

On international comparison, Austria, Switzerland and Germany show the lowest per-capita consumption of analgesics. In Sweden and France consumption is three times as high, which is attributed to the high increase in single products over the past 15-20 years. It is difficult to assess to what extent these differences can be explained by different prevalences of painful disorders, such as shown for headache disorders at least for various world regions [2], since the required country-specific data are not available.

Recently, consumption of single analgesics has increased slightly in Germany and Switzerland. Austria today has the lowest proportion of single products in international comparison. In the USA a decrease in the use of single products is accompanied by a decrease in overall analgesic consumption. The correlation analysis over the different countries and time points confirms the positive correlation between use of single analgesics and overall analgesics consumption. Caffeine-containing multiple combinations containing two analgesic agents plus caffeine are of minor relevance in international comparison and thus cannot be causally related to the sharply rising overall consumption in some countries. The correlation analysis also shows that this product group does not contribute to the high analgesic consumption on a population level-on the contrary it rather counteracts this phenomenon.

In Germany per-capita consumption of analgesics has remained nearly unchanged at approx. $50 \mathrm{SU}$ per capita per year since 1980 . It is currently 52 SU per capita per year and thus slightly higher than the long-term average. There is no difference between Germany (West) and Germany (all). These consumption figures, which are very stable in international comparison, were already seen from 1970 to 1986 [1]. They varied between 47 and 54 SU per capita per year, with a continuous decrease after 1979, the year with the highest consumption. Two-thirds of the current per-capita consumption in Germany comprises OTC analgesics. The increase in the use of prescription drugs since 1995 has led to a slight increase in overall consumption, which is now back at the level of 1986. This could be explained by an increasing number (possibly age-related) pain patients or a certain previous undersupply with analgesics of the latter. Phenacetin-containing analgesics, which in the 1970s still held a market share of up to $40 \%$, were taken from the market in 1986. Caffeine-containing analgesics have shown a continuous decrease (by approx. 1 SU per year) since 1980.

For all OTC analgesics (except the $400 \mathrm{mg}$ ibuprofen products) the recommended dose is one to two tablets three times daily. The epidemiological headache study conducted by the German Migraine and Headache Society between 2003 and 2005 (first results were presented at the German Pain Congress 2006) showed that the headache prevalence over 1 year is approx. $60 \%$ and that about onethird of the German adult population suffer from headaches more than once per month. If we assume that these patients suffer from their migraine or headaches for 2-3 days per month and that they treat their condition with half the recommended maximum daily dose, i.e. $3 \times 1$ tablet per day, we receive a calculated per-capita consumption of $40 \mathrm{SU}$ per year for the total population (estimated $45 \%$ affected). The appropriate use of analgesics for the selftreatment of these indications alone can explain the percapita consumption of approx. $40 \mathrm{SU}$ per year. Some of the affected people will undoubtedly successfully treat their headaches without medication or with an even lower daily dose. In addition to headache treatment, there is the treatment of pain of other etiologies (e.g. toothache, menstruation-induced pain, cold-induced pain, low back pain) and almost all analgesic use prescribed by doctors. Consequently the consumption figures in Germany and other countries do not support the claim of an inappropriately high use of analgesics on a population level. The prevalence of the conditions in which analgesic use is indicated, as the most relevant criterion for analgesic consumption, is frequently underestimated. Although we definitely do not wish to trivialise the risks of analgesic abuse in general, or of medication overuse headache in particular, it is important to realise that estimates from analgesic consumption studies on population level as this are not adequate to provide scientifically founded data on analgesic consumption by specific patient groups.

In conclusion, it has been shown that great differences exist in the per-capita consumption of analgesics between 
different countries. These differences seem to be due to the impact of single analgesics: countries with increasing amounts of single analgesics likewise show an increase in their total supplies of analgesics. In countries such as Austria, where consumption with single analgesics is decreasing, the total consumption of analgesics also decreases and actually shows the lowest per-capita consumption among the considered countries. On the other hand, there is no correlation between the consumption of caffeine-containing analgesics and total analgesic consumption. Per-capita use of analgesics in Germany has been relatively stable at approx. $50 \mathrm{SU}$ per capita per year over the past 25 years. There is no difference between Germany (West) and Germany (all). Taking into account the prevalence of the conditions prompting analgesics consumption, we can conclude appropriate use of analgesics on total population level.
Conflict of interest Prof. Dr. Hans-Christoph Diener received honoraria for participation in clinical trials, contribution to advisory boards or oral presentations from: Addex Pharma, Allergan, Almirall, AstraZeneca, Bayer Vital, Berlin Chemie, CoLucid, Boehringer Ingelheim, Bristol-Myers Squibb, GlaxoSmithKline, Grünenthal, Janssen-Cilag, Lilly, La Roche, 3M Medica, MSD, Novartis, Johnson \& Johnson, Pierre Fabre, Pfizer, Schaper and Brümmer, SanofiAventis, Weber \& Weber. Financial support for research projects was provided by Allergan, Almirall, AstraZeneca, Bayer, GSK, Janssen-Cilag, Pfizer. Headache research at the Department of Neurology in Essen is supported by the German Research Council (DFG), the German Ministry of Education and Research (BMBF) and the European Union. H. C. Diener has no ownership interest and does not own stocks of any pharmaceutical company. Dr. Roland Schneider and Dr. Bernhard Aicher are employees of Boehringer Ingelheim Pharma GmbH \& Co. KG.

\section{Appendix 1}

Table 2

Table 2 Example for an SU calculation

\begin{tabular}{|c|c|c|c|c|c|c|}
\hline \multirow[t]{2}{*}{ Country A } & (a) & (b) & (c) & \multirow{2}{*}{$\begin{array}{l}\text { (d) } \\
\text { (a) } \times(b)(a) \times(c / \text { factor }) \\
\text { SU }\end{array}$} & (e) & $\begin{array}{l}\text { (f) } \\
\text { (d)/(e) }\end{array}$ \\
\hline & $\begin{array}{l}\text { Packs per } \\
\text { year }(000)\end{array}$ & $\begin{array}{l}\text { Tablets } \\
\text { per pack }\end{array}$ & $\begin{array}{l}\text { Ml liquid } \\
\text { per pack }\end{array}$ & & $\begin{array}{l}\text { Inhabitants } \\
(000)\end{array}$ & $\begin{array}{l}\text { Per-capita } \\
\text { consumption }\end{array}$ \\
\hline \multicolumn{7}{|l|}{ Year 2000} \\
\hline \multirow[t]{2}{*}{ ASA } & 800 & 20 & & 16,000 & & \\
\hline & 600 & 30 & & 18,000 & & \\
\hline \multirow[t]{3}{*}{ Paracetamol } & 1,000 & 10 & & 10,000 & & \\
\hline & 400 & 30 & & 12,000 & & \\
\hline & 500 & & 250 & 12,500 & & \\
\hline Total & & & & 68,500 & 1,500 & 46 \\
\hline \multicolumn{7}{|l|}{ Year 2005} \\
\hline \multirow[t]{2}{*}{ ASA } & 700 & 20 & & 14,000 & & \\
\hline & 900 & 30 & & 27,000 & & \\
\hline \multirow[t]{3}{*}{ Paracetamol } & 800 & 10 & & 8,000 & & \\
\hline & 350 & 30 & & 10,500 & & \\
\hline & 450 & & 200 & 9,000 & & \\
\hline Total & & & & 68,500 & 1,400 & 49 \\
\hline
\end{tabular}

\section{References}

1. Stovner LJ K, Hagen K, Jensen R, Katsarava Z, Lipton RB, Scher AI, Steiner TJ, Zwart J-A (2007) The global burden of headache: a documentation of headache prevalence and disability worldwide. Cephalalgia 27:193-210
2. Mahecha LM (2006) Rx-to-OTC switches: trends and factors underlying success. Nat Rev Drug Discov 5(5):380-385

3. Meiner E (1987) Analgetika-Verbrauch in Deutschland und ausgewählten Ländern. Pharm Ind 49:1247-1251 